\title{
Análise de mercado: produção de morangos e manjericões
}

\author{
Walter Roberto Hernández \\ Vergara \\ waltervergara@ufgd.edu.br \\ Universidade Federal da Grande \\ Dourados (UFGD), Dourados, Mato \\ Grosso do Sul, Brasil. \\ Juliana Suemi Yamanari \\ jusuemi@hotmail.com \\ Universidade de São Paulo (USP), São \\ Carlos, São Paulo, Brasil. \\ Fabio Alves Barbosa \\ fabiobarbosa@ufgd.edu.br \\ fabiobarbosa@ufgd.edu.br da Grande \\ Universidade Federal da Grande
Dourados (UFGD), Dourados, Mato \\ Grosso do Sul, Brasil. \\ Keylla Barboza Santos \\ Keylla_bsantos@hotmail.com \\ Universidade Federal da Grande \\ Dourados (UFGD), Dourados, Mato \\ Grosso do Sul, Brasil.
}

\begin{abstract}
RESUMO
O potencial de desenvolvimento e empreendedorismo sempre foi um predicado para descrever o agronegócio brasileiro, principalmente nos últimos anos. Nas últimas décadas, o setor se tornou foco de grandes desenvolvimentos e oportunidades na área de irrigação, onde a floricultura foi se destacando de forma empresarial sem viés apenas para a subsistência e cultura assistencialista. Nesse sentido, o objetivo dessa pesquisa quantitativa é realizar uma análise de mercado que mapeie e identifique o segmento de mercado consumidor do cultivo de morango e manjericões hidropônicos, demonstrando a viabilidade de um novo empreendimento nesse ramo. O estudo tem natureza bibliográfica, exploratória, descritiva, explicativa e foi realizado no estado do Mato Grosso do Sul no período de 2017 a 2018. Os resultados apontaram, através das análises realizadas no âmbito mercadológico, que o referido segmento de mercado está em constante expansão e com investimento adequado e esforço tecnológico, é possível criar muitas oportunidades relacionadas à agricultura familiar.
\end{abstract}

PALAVRAS-CHAVE: Análise de mercado. Agronegócio. Agricultura familiar. 


\section{INTRODUÇÃO}

Garantir a segurança alimentar é um dos principais desafios do século 21 nos países em desenvolvimento (ISSA et al., 2019). Nesse sentido a agricultura familiar viabiliza o desenvolvimento local fornecendo sustentabilidade econômica e social, pois colabora com a geração de renda e emprego no campo, ou seja, muitas famílias vivem da venda de produtos produzidos em sua propriedade e colaboram com a geração de postos de trabalhos para o cultivo da produção (TONNEAU; SABOURIN, 2007; NEVES; NEVES, 2007). Além disso, segundo informações do Portal Brasil e da Casa Civil (2016), essa atividade é responsável por fornecer cerca de $70 \%$ dos alimentos consumidos no país.

Dada a importância da agricultura familiar, a análise de mercado para um futuro investimento no setor visa contribuir com o empreendedor que busca além de sobreviver do negócio, viver com suas necessidades básicas sanadas e com o mínimo de conforto (SOUZA et al., 2012). Portanto, a análise desta pesquisa busca demonstrar se o investimento é viável sob o ponto de vista mercadológico.

O estudo de análise de mercado foi realizado com base na introdução da cultura de morango e manjericão hidropônicos em uma agricultura familiar, próxima à cidade de Campo Grande/MS. Uma das motivações do trabalho foi a necessidade de sustento de uma família carente e da baixa frequência desses produtos no mercado.

A hidroponia é uma das tecnologias agrícolas que está sendo considerada o setor de crescimento mais rápido da agricultura e pode governar a produção de alimentos no futuro. A agricultura hidropônica fornece a quantidade e o tipo certos de nutrientes que as plantas precisam no momento certo e podem ser instalados em ambientes internos para maximizar o espaço disponível. Os problemas relacionados ao solo foram resolvidos através da hidroponia como, por exemplo, plantas em crescimento que necessitavam de condições específicas do solo e colheita mais sensível (MELCHIZEDEK et al., 2019).

A produção será implantada em uma chácara a menos de 20 quilômetros da cidade de Campo Grande, estando próximo ao maior centro comercial, onde segundo dados do Ceasa-MS em 2016 houve um consumo de aproximadamente 816 toneladas no país, e produção de um pouco mais de 1 tonelada de morangos no Estado, já de manjericão, produziu-se aproximadamente 13 toneladas (CEASA, 2016).

Os produtos serão o morango da espécie Camino Real, o manjericão de Folha Larga, também conhecido como Alfavaca ou manjericão Italiano e o manjericão de Folha Roxa. A princípio, o cultivo começará com 9.600 plantas de morango e 3.068 plantas de manjericão.

O principal consumidor para o morango e os manjericões será o Ceasa-MS e, posteriormente, os possíveis futuros consumidores para o morango poderão ser restaurantes, hotéis, padarias, confeitarias e buffets. No caso do manjericão, serão restaurantes gourmet, pizzarias, hotéis e buffets. Os produtos oferecidos terão condições mais saudáveis ( $0 \%$ de agrotóxicos para o manjericão e uma taxa mínima para os morangos) e de qualidade, durante o ano todo. Além disso, esses produtos devem ser apresentados com preços competitivos e percentuais de 
descontos de acordo com a quantidade comprada. Também, são considerados a realização de novas parcerias e a fidelização de clientes.

A pesquisa em questão tem como objetivo realizar uma análise de mercado, para posteriormente ser utilizada em um plano de negócio que estude a viabilidade econômico-financeira da implantação da cultura de morango e manjericão hidropônicos em uma agricultura familiar. Após o estudo, espera-se confirmar o sucesso da atividade e oferecer maior segurança financeira à família, bem como contribuir com o aumento da oferta desses produtos no mercado. Além disso, com os dados quantitativos analisados, a pesquisa poderá servir de base para a elaboração de estratégias e planos de ação para futuros empreendimentos nesse ramo.

\section{PROCEDIMENTOS METODOLÓGICOS}

A presente pesquisa utilizou fontes como livros, publicações digitais e websites da internet. Caracteriza-se como descritiva (GIL, 2002; GIL, 2007) com a finalidade de registrar e analisar as informações, com fatos e fenômenos da realidade estudada. Segundo Vergara (2007) e Barros e Lehfeld (2007), a pesquisa descritiva mostra as características de uma determinada população, interpretando a realidade do objeto em estudo sem interferir e modificar o mesmo.

Também pode ser considerada uma pesquisa exploratória pois foram realizadas entrevistas informais com produtores e pessoas peritas, pesquisas de campo e investigação de outros exemplos para aprofundar o conhecimento do contexto do assunto estudado.

Para a presente pesquisa, optou-se por utilizar um instrumento de gestão empresarial, a análise de mercado, que, segundo Porter (1999), permite através da avaliação completa de consumidores, concorrência, fornecedores e do mercado da empresa, estabelecer objetivos e determinar estratégias para que os mesmos sejam atingidos.

Desenvolver uma estratégia consiste em traçar linhas de ação no segmento de mercado na qual a empresa vai concorrer, quais devem ser seus objetivos e quais serão suas estratégias para alcançar tais objetivos. Nesse sentido, os seguintes tópicos foram considerados na análise do estudo de mercado:

- Caracterizar a oferta e a demanda dos produtos;

- Quantificar dados para projetar a oferta e a demanda;

- Capacidade de produção instalada e utilizada;

- Projetar a capacidade de produção;

- Caracterizar e segmentar o mercado;

- Determinar o público alvo, suas necessidades e seus principais comportamentos de compra;

- Análise da concorrência e sua estrutura;

- Análise de fornecedores;

- Canais e estrutura de comercialização. 
A obtenção dos dados foi feita pela coleta de informações no Instituto Brasileiro de Geografia e Estatística (IBGE) que contém os dados demográficos da população brasileira, Sebrae que reúne informações sobre a produção de produtos hidropônicos e sobre diversos aspectos que podem impactar os negócios brasileiros. Também a plataforma Google Trends que contém informações sobre tendências através de dados de buscas por termos e da bibliografia empresarial, onde foram selecionados uma variedade de variáveis e indicadores micro e macroeconômicos com seus respectivos dados, buscando-se assim, aplicar os diferentes métodos e técnicas estatísticas para que as informações obtidas possam subsidiar a tomada de decisões estratégicas para o negócio.

Compilados os dados, estes em seguida foram submetidos à análise estatística usando o Microsoft Office Excel, por meio de suas funções e bibliotecas para obtenção dos valores de correlação, variância, construção de gráficos e modelos de processamento de dados.

\section{RESULTADOS E DISCUSSÕES}

Os produtos analisados para um possível empreendimento serão o manjericão de folha larga (alfavaca) e de folha roxa hidropônico, e morangos Camino real semi-hidropônicos.

\section{MORANGO SEMI-HIDROPÔNICO}

Os benefícios de consumir essa fruta cítrica de sabor adocicado são inúmeros à saúde como por exemplo, de acordo com o portal de notícias $R 7$ (R7, 2016), um estudo apresentado pelo Journal of the Agriculture and Food Chemistry mostrou que as antocianinas também presentes nos morangos auxiliam na queima de gorduras. Os morangos podem ser consumidos de diversas maneiras, como in natura, em vitaminas, sucos, geleias etc. (BELEZAESAUDE, 2016).

Atualmente no Estado do Mato Grosso do Sul não existem produtores de morango suficientes para suprir a demanda do mercado. Esse produto vem de outros Estados principalmente, São Paulo, Minas Gerais e Rio Grande do Sul, e devido à distância, as frutas precisam ser colhidas antes do amadurecimento. Assim, essa fruta apresenta característica nutricionais reduzidas, sendo não muito doces e com pouca acidez em seu sabor.

Caso os morangos fossem produzidos no Estado do Mato Grosso do Sul, em Campo Grande mais precisamente, poderiam ser colhidos mais tardiamente, após um desenvolvimento considerável do fruto, produzindo assim morangos maiores, suculentos, vermelhos, mais saborosos e com maior valor nutricional, sem a utilização de agrotóxicos e podendo ser produzido durante todo o ano por conta da hidroponia, além do controle ser realizado dentro da estufa.

Os morangos in natura podem ser entregues aos clientes em cumbucas com tampa de plástico (PET) apresentadas pela Figura 1, de dimensão $16,5 \times 9,5 \times 3 \mathrm{~cm}$, de coloração transparente e com peso de $310 \mathrm{~g}$. Para facilitar o carregamento e não prejudicar a qualidade das frutas, poderão ser colocadas em caixas de 
papelão (ver Figura 2). A entrega pode ocorrer semanalmente ou de acordo com sua demanda.

Figura 1 - Embalagem individual do morango

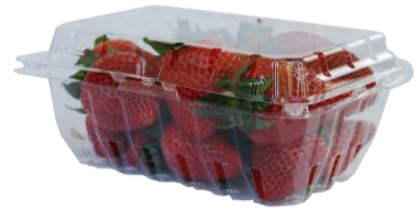

Fonte: Autoria própria (2018)

Figura 2 - Embalagem conjunta de morangos

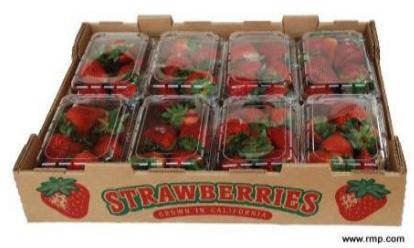

Fonte: Autoria própria (2018)

\section{MANJERICÃO HIDROPÔNICO}

O manjericão é utilizado na culinária como tempero e/ou na medicina alternativa, como ingrediente para realização de chás e óleos essenciais, pois essa planta apresenta vitaminas que são excelentes à saúde (BELEZAESAUDE, 2016). Por conta da extensa utilização, e pela oportunidade presente no mercado sul-mato-grossense, o manjericão foi escolhido para ser a segunda cultura a ser analisada para cultivo.

O principal consumidor dos manjericões hidropônico mapeado foi o CeasaMS e, durante o período serão elaboradas estratégias de marketing direcionadas para outros possíveis compradores/consumidores como restaurantes, buffets, hotéis e pizzarias, já que estes estabelecimentos utilizam as folhas do manjericão no preparo de seus pratos deixando um sabor especial, além de beneficiar as pessoas que buscam comer de forma mais saudável, em vista que não são utilizados agrotóxicos em sua produção.

No sistema de distribuição dos manjericões de folha larga e roxo, os maços podem ser separados em sacolas plásticas próprias e individuais de dimensões $14 \times 34 \times 34 \mathrm{~cm}$, e armazenados em caixas de papelão, que dependendo da quantidade solicitada será colocada em um dos três tamanhos de caixas disponíveis, deixando o maço no sentido vertical lado a lado, facilitando assim, a armazenagem e transporte. Além disso, é possível manter o produto sempre fresco colocando-o dentro de um recipiente com água por aproximadamente duas semanas. 
Figura 3 - Manjericão Folha Larga

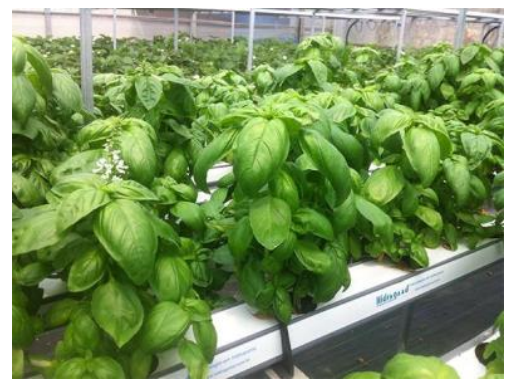

Fonte: Autoria própria (2018)

Figura 4 - Manjericão Folha Roxa

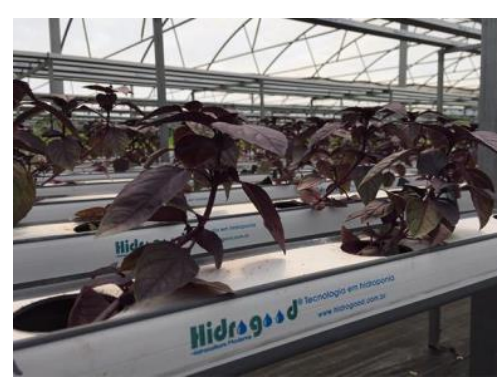

Fonte: Autoria própria (2018)

\section{CICLO DE VIDA DOS PRODUTOS}

Segundo Bernardi e Hoffman (2006), as mudas de morango do tipo camino real devem ser colocadas em slabs, onde são preenchidas por substrato ou matrix, que podem ser compostos por turfa de esfagno, vermiculita expandida, casca de arroz carbonizada, calcário dolomítico, gesso agrícola, fertilizante NPK e micronutrientes, na qual a planta irá se apoiar. A solução nutritiva é administrada de modo automatizado, uma média de $100 \mathrm{ml}$ por planta/dia. Cada muda demora cerca de dois meses para começar a produzir os frutos e terão uma vida útil de dois anos, depois disso devem ser substituídas por mudas novas, assim como os slabs utilizados. Já o seu fruto deve ser consumido em até três dias após colhido ou deve ser mantido congelado por até duas semanas.

No caso das mudas de manjericão, segundo Silva e Melo (2003) e Sebrae (2017b) os dois tipos são cultivados no sistema hidropônico, no qual a substância nutritiva passa pelos perfis hidrogood, parecidos com canos de PVC, nos quais as plantas crescem continuamente. As plantas passam doze dias no berçário, onde serão germinadas, e posteriormente são postas nas bancadas onde irão produzir. As verduras folhosas começam a produzir em cerca de três semanas. $O$ ciclo total varia de 30 a 40 dias, de acordo com o nível de maturação desejado e depois de colhido a verdura pode ser mantida fresca por até duas semanas se colocada em um recipiente com água.

Segundo Loschiavo (2016), o ciclo de vida dos produtos hidropônicos é diferenciado se comparado aos produtos orgânicos. Por isso é considerado um método relativamente novo e um grande avanço para agricultura. No caso do morango, o orgânico leva de sessenta a oitenta dias para começar a produzir e pode ser colhido apenas pelos próximos 4 meses seguidos, geralmente de janeiro 
a abril, enquanto que os hidropônicos e semi-hidropônicos podem produzir pelos próximos dois anos subsequentes, resguardando o produtor dos problemas relacionados à sazonalidade, além de evitar contaminação da raiz, por não ir ao solo, e reduzir o uso de pesticidas em mais de $70 \%$, devido ao ambiente controlado.

Referente ao ciclo de vida do manjericão orgânico, além dos muitos cuidados em relação a sua produção por ser uma planta sensível, sua versão orgânica sofre muito com ataques de lesmas, pulgões, lagartas, entre outras pestes, tendo que utilizar agrotóxicos para controle das plantações, além dos riscos com contaminação da planta. Segundo o Sebrae (2017b), a produção hidropônica do manjericão possibilita a produção da verdura folhosa sem necessidade de utilização de nenhum tipo de defensivo agrícola, tornando a verdura $100 \%$ limpa de agrotóxicos e ainda mais saudável, visto que é possível controlar a quantidade de nutrientes e o nível de maturação da planta.

\section{ANÁLISE DO MERCADO DE HORTIFRUTIGRANJEIRO DO MS}

Segundo Maldonado (2014), apesar de conhecido como grande produtor rural, Mato Grosso do Sul não produz a quantidade necessária para suprir a necessidade do Estado de frutas, verduras e legumes. De tudo que é consumido e comercializado dentro do Estado apenas 14,49\% é produzido nele mesmo, enquanto os outros $85,51 \%$ são importados de outros Estados brasileiros, como, por exemplo, Santa Catarina, Rio Grande do Sul, São Paulo, Minas Gerais, Paraná, entre outros.

Em 2013 houve negociação de cerca de 170 mil toneladas pelo Ceasa-MS, sendo que desse valor apenas 24,1 toneladas eram de produtos internos do MS. E ainda segundo dados do Ceasa-MS, em 2016 o Estado produziu apenas o equivalente a $10 \%$ das frutas consumidas internamente. A única categoria em que o Estado pode ser considerado autossuficiente e grande exportador é no caso das verduras folhosas, como é o caso do manjericão.

As condições climáticas são os maiores influenciadores para a criação do cenário hortifrutigranjeiro sul mato-grossense. Dependendo do tempo se pode ou não produzir determinados produtos. Isso deixa à mercê o Estado dos produtores de fora que negociam seus produtos para MS. Além disso, de acordo com o período que ocorre a negociação, se o produto negociado está fora de época de cultivo, os preços podem chegar a custar até $200 \%$ do seu real valor. Esse é, por exemplo, o caso do morango, que é um produto considerado sazonal e que consegue ser produzido fora de época em poucas regiões.

Segundo dados do site do Ceasa-MS (2016), de um total de aproximadamente 861 toneladas de morangos, apenas 1 tonelada foi produzida em Mato Grosso do Sul, que equivale a cerca de $0,0022 \%$ da produção total. No caso do manjericão teve uma produção total de aproximadamente 13 toneladas de 14,6 toneladas produzidas no total, que é o equivalente a $89,22 \%$.

No caso do manjericão, o Estado é o maior produtor, produzindo sozinho cerca de $89 \%$ do total, o que o torna o maior produtor e importador dessa verdura folhosa. O fato do manjericão, tanto de folha larga quanto de folhas roxas, não ser produzido em outros Estados, além de São Paulo e Santa Catarina, onde tem uma taxa de produção muito baixa, o torna um produto elegível na 
escolha do que produzir. Além disso, o fato de ser também um produto hidropônico o torna ainda mais atrativo para o mercado de exportação, considerando um planejamento logístico eficiente que identifique e controle todas as variáveis que interferem no transporte e na armazenagem do produto de forma correta, em vista que pode permanecer fresco por até duas semanas depois de colhido e embalado.

Levando em consideração todos os dados apontados até aqui, entende-se que a melhor forma de introduzir os produtos no mercado, será através de vendas diretas no Ceasa-MS, onde será garantida a venda de todos os produtos, mesmo que a um preço um pouco abaixo do mercado, em que os representantes locais farão todo o intermédio até os consumidores, que podem ser restaurantes, mercados, frutarias, sacolões, etc. Após consolidado o produto, será possível através do plano de marketing chegar diretamente a esses compradores, criando parcerias, expandindo o público alvo e aumentando o poder de mercado da marca.

O público alvo futuro, citado anteriormente, trata-se de frutarias, confeitarias, buffets, docerias, restaurantes, lanchonetes, grandes hotéis etc., onde seja possível a venda dos morangos para todo tipo de fins alimentícios e dos manjericões para utilização na culinária como temperos gourmet.

O consumo do morango não se restringe a nenhuma condição racial, etária e religiosa, podendo ser comercializado em qualquer segmento alimentício. Enquanto o manjericão pode ser segmentado para um público mais refinado, por se tratar de um tempero gourmet, diminuindo o público comprador para restaurantes, buffets e estabelecimentos de comidas saudáveis e/ou fitness. Contudo, pode-se afirmar que existe um mercado promissor que com pequenos investimentos e uso de tecnologia pode apresentar novas oportunidades de negócios para produtores de morango.

\section{A análise dos consumidores}

Levando-se em consideração o consumo total de morangos em todo país, que é equivalente a aproximadamente $861.319,10 \mathrm{Kg}$ de morango ao ano, é possível encontrar o consumo brasileiro por pessoa de 0,00418 $\mathrm{Kg}$. Com esse dado, tem-se uma média de consumo total para o Estado de Mato Grosso do Sul, que é cerca de 11 toneladas de morango/ano (Tabela 1).

Tabela 1 - Consumo de morangos

\begin{tabular}{cccc|c}
$\begin{array}{c}\text { Consumo de } \\
\text { morangos (BR) - Kg }\end{array}$ & $\begin{array}{c}\text { População } \\
\text { Brasil }\end{array}$ & $\begin{array}{c}\text { Consumo por } \\
\text { pessoa (BR) }\end{array}$ & $\begin{array}{c}\text { Consulação MS } \\
\mathrm{kg}\end{array}$ & $\begin{array}{c}\text { Consumo } \\
\text { total (MS) - kg }\end{array}$ \\
\hline $861.319,10$ & 206.000 .000 & 0,00418 & 2.682 .386 & $11.215,49$ \\
\hline
\end{tabular}

Fonte: Autoria própria (2018)

Da mesma forma, pode-se calcular a oferta anual de manjericão do país que é de $14.601,50 \mathrm{Kg}$ e com isso, calcular um consumo de $0,00007 \mathrm{Kg} /$ pessoa e 190,13 Kg para o Estado do MS (Tabela 2). 
Tabela 2 - Consumo de manjericão

\begin{tabular}{ccccc}
$\begin{array}{c}\text { Consumo de } \\
\text { manjericão (BR) - kg }\end{array}$ & $\begin{array}{c}\text { População } \\
\text { Brasil }\end{array}$ & $\begin{array}{c}\text { Consumo por } \\
\text { pessoa (BR) } \\
\mathrm{kg}\end{array}$ & $\begin{array}{c}\text { População MS } \\
\text { total (MS) - kg }\end{array}$ & $\begin{array}{c}\text { Consumo } \\
\text { total }\end{array}$ \\
\hline $14.601,50$ & 206.000 .000 & 0,00007 & 2.682 .386 & 190,13 \\
\hline
\end{tabular}

Fonte: Autoria própria (2018)

Através desses dados, observa-se que apesar da necessidade de 11,2 toneladas de morango, o Estado consegue suprir apenas 9,13\% do valor demandado, com exatos $1.024,50 \mathrm{Kg}$ de morango, enquanto todo o restante é suprido através da importação de outros Estados brasileiros. Já no caso do manjericão, apesar de uma necessidade média de apenas $190 \mathrm{Kg}$, o Estado produz $13.027,40 \mathrm{Kg}$, porém é responsável por quase $90 \%$ da produção nacional, abastecendo assim vários outros Estados.

Pode-se afirmar que independentemente da quantidade produzida de morangos e manjericões, toda produção será consumida, por conta do déficit no Estado, para o morango, e do país para o manjericão. Nas Tabelas 3 e 4 são apresentados o consumo e os preços nos últimos 16 meses.

Tabela 3 - Preço e demanda do morango

\begin{tabular}{cccr} 
Mês & Quantidade (kg) & \multicolumn{2}{c}{ Preço } \\
jan/16 & 533,09 & $\mathrm{R} \$$ & 13,44 \\
$\mathrm{fev} / 16$ & 813,86 & $\mathrm{R} \$$ & 12,53 \\
$\mathrm{mar} / 16$ & 384,21 & $\mathrm{R} \$$ & 13,57 \\
$\mathrm{abr} / 16$ & 376,48 & $\mathrm{R} \$$ & 15,83 \\
$\mathrm{mai} / 16$ & 392,92 & $\mathrm{R} \$$ & 15,81 \\
$\mathrm{jun} / 16$ & 612,91 & $\mathrm{R} \$$ & 15,21 \\
$\mathrm{jul} / 16$ & $1.100,33$ & $\mathrm{R} \$$ & 13,93 \\
$\mathrm{ago} / 16$ & $1.853,49$ & $\mathrm{R} \$$ & 9,95 \\
$\mathrm{set} / 16$ & $1.346,71$ & $\mathrm{R} \$$ & 9,42 \\
out/16 & $1.309,24$ & $\mathrm{R} \$$ & 10,44 \\
$\mathrm{nov} / 16$ & $1.087,21$ & $\mathrm{R} \$$ & 10,10 \\
$\mathrm{dez} / 16$ & $1.405,05$ & $\mathrm{R} \$$ & 9,01 \\
$\mathrm{jan} / 17$ & 184,52 & $\mathrm{R} \$$ & 11,39 \\
$\mathrm{fev} / 17$ & 181,98 & $\mathrm{R} \$$ & 10,53 \\
$\mathrm{mar} / 17$ & 203,10 & $\mathrm{R} \$$ & 10,00 \\
$\mathrm{abr} / 17$ & 176,72 & $\mathrm{R} \$$ & 11,61 \\
\hline
\end{tabular}

Fonte: Autoria própria (2017)

Tabela 4 - Preço e demanda do manjericão

\begin{tabular}{cccc} 
Mês & Quantidade $(\mathrm{kg})$ & \multicolumn{2}{c}{ Preço } \\
jan/16 & 975,10 & $\mathrm{R} \$$ & 2,50 \\
$\mathrm{fev} / 16$ & $1.319,15$ & $\mathrm{R} \$$ & 2,50 \\
$\mathrm{mar} / 16$ & $1.414,00$ & $\mathrm{R} \$$ & 2,50 \\
$\mathrm{abr} / 16$ & $1.389,15$ & $\mathrm{R} \$$ & 2,50 \\
$\mathrm{mai} / 16$ & $1.374,80$ & $\mathrm{R} \$$ & 2,50 \\
$\mathrm{jun} / 16$ & $1.026,55$ & $\mathrm{R} \$$ & 2,50 \\
$\mathrm{jul} / 16$ & 982,10 & $\mathrm{R} \$$ & 2,50 \\
$\mathrm{ago} / 16$ & 929,60 & $\mathrm{R} \$$ & 2,50 \\
$\mathrm{set} / 16$ & 929,95 & $\mathrm{R} \$$ & 2,50 \\
out $/ 16$ & 786,60 & $\mathrm{R} \$$ & 2,50
\end{tabular}




\begin{tabular}{cccc} 
Mês & Quantidade $(\mathrm{kg})$ & \multicolumn{2}{c}{ Preço } \\
nov/16 & $1.461,65$ & $\mathrm{R} \$$ & 2,50 \\
$\mathrm{dez} / 16$ & $2.012,85$ & $\mathrm{R} \$$ & 2,50 \\
$\mathrm{jan} / 17$ & $14.423,03$ & $\mathrm{R} \$$ & 2,50 \\
$\mathrm{fev} / 17$ & $14.230,74$ & $\mathrm{R} \$$ & 2,50 \\
$\mathrm{mar} / 17$ & $15.284,48$ & $\mathrm{R} \$$ & 2,50 \\
$\mathrm{abr} / 17$ & $13.727,63$ & $\mathrm{R} \$$ & 2,50 \\
\hline
\end{tabular}

Fonte: Autoria própria (2017)

Utilizando os dados do IBGE (2017) para previsão da população do Estado para os próximos 5 (cinco) anos e a média do consumo por pessoa, foi possível prever a demanda anual de morangos e manjericões até o ano de 2021. Na Tabela 5 é apresentado o resultado do cálculo da demanda para morangos. 0 método de estimação utilizado foi o procedimento da média móvel centrada que é utilizada onde existe sazonalidade. No caso da demanda de manjericões a previsão foi realizada pelo método de regressão linear. Também observamos na tabela a demanda total para o ano 2017.

Segundo Martins e Laugeni (2015), a previsão é um processo metodológico que é utilizado para estimar dados futuros em modelos matemáticos, estatísticos ou econométricos. A escolha do método depende da natureza do produto e de outros fatores, tais como dados históricos, horizonte da previsão, precisão exigida etc. Assim, dois tipos de modelos básicos são utilizados: modelos de séries temporais e modelos causais.

Nos modelos de séries temporais encontramos quatro condicionantes: tendência, variação cíclica, variação aleatória e variação sazonal.

A variação sazonal são flutuações que não necessariamente são regulares e, normalmente, se repetem em períodos quase sempre coincidindo com o calendário anual ou mensal. Ela é o resultado de causas naturais, econômicas ou institucionais. Na aplicação do método, o índice de sazonalidade é obtido na forma de quantidade ou porcentagem e esse valor é aplicado sobre a média ou a tendência que se desvia dos valores médios da série.

O cálculo da média móvel centrada é obtido através da Equação 1.

$$
M M C_{t}=\frac{D_{t}+D_{t-1}+D_{t-2}+\cdots+D_{t-(n+1)}}{n}
$$

Onde Dt são as demandas $(t=1,2,3, \ldots, n)$ do ciclo sazonal e $n$ é o número de períodos considerados na média móvel.

$\mathrm{O}$ índice de sazonalidade é obtido através da Equação 2.

$$
I S_{t}=\frac{D_{t}}{M M C_{t}}
$$

onde Dt é a demanda no período $t,(t=1,2,3, \ldots, n)$ e MMCt é a média móvel centrada neste período.

Por outro lado, a análise de regressão é um procedimento estatístico que tem como objetivo verificar a existência de uma relação causal entre um conjunto de variáveis. Ela permite a construção de uma equação linear que tenta explicar o comportamento de uma variável dependente em relação a uma ou mais variáveis independentes (VERGARA, 2017). Essa equação é obtida pela adaptação de um conjunto de pares ordenados das variáveis, por meio de dados 
históricos coletados. Quando a função envolve uma relação causal entre duas variáveis, temos um modelo de regressão simples.

O modelo estatístico básico para uma regressão linear simples tem a forma da Equação 3:

$$
y=\alpha+\beta x+\varepsilon
$$

Onde $\alpha$ e $\beta$ são constantes e representam os coeficientes linear e angular, respectivamente. $O$ fator $\varepsilon$ representa o erro, isto é, a variação de y que não é explicada pelo modelo. $O$ coeficiente linear indica onde a reta intercepta o eixo $y$, enquanto o coeficiente angular ou de inclinação indica a variação de y em função da variação de uma unidade de x (VERGARA, 2017).

Tabela 5 - Previsão de demanda para os próximos 5 anos

\begin{tabular}{ccc}
\hline Perído & Demanda morango & Demanda manjericão \\
\hline 2017 & 1524,45 & 14,68 \\
& 456,88 & 14,89 \\
& 970,93 & 15,10 \\
& 712,18 & 15,31 \\
& 661,34 & 15,52 \\
& 491,14 & 15,73 \\
& 480,34 & 15,94 \\
& 694,94 & 16,15 \\
& 1025,30 & 16,36 \\
& 746,72 & 16,58 \\
2018 & 789,17 & 16,79 \\
2019 & 846,26 & 17,00 \\
2020 & 9399,65 & 190,06 \\
2021 & 955,79 & 194,44 \\
\hline
\end{tabular}

Fonte: Autoria própria (2018)

Quanto ao perfil dos consumidores, podemos classificá-los por seção e subseções, já que a priori os produtos serão vendidos ao Ceasa-MS e os intermediários farão a revenda e distribuição pelo Estado ou exportação. $O$ Ceasa-MS compra de acordo com a necessidade do mercado tanto para consumo interno como para exportação para outros Estados. No Ceasa-MS existem diversos tipos de perfis de consumidores formando as subseções.

Para aqueles que irão revender o produto, mercados por exemplo, as tomadas de decisões vão depender de acordo com a época, perfil dos consumidores de sua microrregião, preços etc. Outra via para quem trabalha com o produto para gerar subprodutos e/ou utilizar em seus pratos ou receitas, como é o caso de restaurantes, por exemplo, independente da época ou preço é necessário que seja feita a compra para manter seus produtos no mercado ou então opta-se por substituir o produto por outro mais acessível durante esse período, porém para a maioria dos estabelecimentos é importante manter seus cardápios e garantir a satisfação de seus clientes.

Muitos restaurantes, doceiras, confeitarias, buffets etc., adquirem o morango tudo ano. Apesar de ser um produto sazonal, nesses períodos eles 
apresentam uma elasticidade de preços elevada. Esse fenômeno econômico se apresenta pela variação percentual na quantidade demandada sobre a variação percentual de preços destes. Assim, o produto se torna mais competitivo.

A produção do morango pelo processo hidropônico não é suscetível a problemas de sazonalidade, uma vez que se produz durante todo ano, podendo concorrer diretamente com os produtos importados com custos mais baixos, porém vendendo a preços mais altos.

\section{Análise da concorrência}

\section{Morangos semi-hidropônicos}

Os concorrentes diretos na produção de morangos dentro do Estado são pequenos produtores, que somados todas as produções são capazes de produzir apenas $15,25 \%$ do total anual que será produzido pelo negócio. As empresas concorrentes estão localizadas nas cidades de Campo Grande, Sidrolândia, Dois Irmãos do Buriti e Terenos, com as respectivas produções de $978 \mathrm{Kg} / \mathrm{ano}, 27$ $\mathrm{Kg} / \mathrm{ano}, 15 \mathrm{Kg} / \mathrm{ano}$ e 4,5 Kg/ano.

Segundo Ceasa-MS, no ano de 2016, Campo Grande teve suas colheitas principais nos meses de fevereiro e março e uma produção adjacente de $3 \mathrm{Kg}$ no mês de novembro; Sidrolândia teve suas produções concentradas nos meses de junho e dezembro; Dois Irmãos do Buriti teve apenas uma colheita no mês de maio; e Terenos teve apenas uma pouco significante colheita no mês de janeiro. Todos esses produtores praticam o cultivo orgânico da fruta, sendo assim não existe nenhum concorrente direto para o empreendimento em sua mesma modalidade.

O preço praticado no mercado para venda no Ceasa-MS é de $\mathrm{R} \$ 13,33$ o quilo do morango, variando de acordo com o período do ano e podendo chegar a até $\mathrm{R} \$ 30,00$ o quilo quando o fruto está fora de época.

\section{Manjericão hidropônico}

Os concorrentes diretos na produção de manjericão, de ambas as espécies que serão produzidas, se encontram em regiões semelhantes a dos concorrentes no cultivo de morango. Estão as concorrentes instaladas nas cidades de Campo Grande, Sidrolândia, Jaraguari e Terenos, e suas respectivas produções no ano de 2016 foram de 10.701,95 Kg/ano, $2.204 \mathrm{Kg} /$ ano, 79,45 Kg/ano e $42 \mathrm{Kg} / \mathrm{ano}$. Campo Grande e Sidrolândia obtiveram uma produção constante durante todo ano, sendo que ambos tiveram a menor colheita no mês de outubro, com 547,05 e $84 \mathrm{Kg}$, e as maiores nos meses de dezembro para a capital de MS e abril para Sidrolândia, sendo de $1.699,95$ e $346,50 \mathrm{Kg}$.

Apesar da grande produção de manjericão dentro do Estado de Mato Grosso do Sul, segundo os dados do Ceasa-MS, a produção fora do Estado é muito insuficiente, chegando ao número de 1.574,1 Kg em 2016, nos Estados de São Paulo e Santa Catarina. Isso faz de MS um grande exportador da verdura para abastecimento de outros Estados brasileiros. Desta forma, mesmo que a produção de manjericão dentro do Estado seja muito alta, ainda existe muito 
mercado para a verdura uma vez que esta é importante para outros locais do país.

Mesmo com o grande volume de produção em MS, principalmente na capital, ainda assim o produto a oferecer pelo empreendimento pode ser considerado um grande concorrente, isso graças ao diferencial oferecido pela hidroponia, que torna o alimento livre de agrotóxicos e por isso mais saudável, além da maior durabilidade do produto. Em pesquisas pela região não pudemos encontrar outros produtores de manjericão hidropônico, seja por não existir ou por ter uma produção ainda muito pequena. Dessa forma não podemos dizer que há um concorrente na mesma categoria, porém os grandes produtores de manjericão orgânico ainda são fortes concorrentes.

Os preços praticados para venda de manjericão estão em torno de $\mathrm{R} \$ 2,50$ o maço de manjericões de folha larga, e entre $\mathrm{R} \$ 3,00$ e RS4,00 para o manjericão de folha roxa. O valor foi obtido pelas tabelas de vendas dos Ceasas e ainda através da observação dos preços dos concorrentes da empresa.

\section{Análise de fornecedores}

A matéria-prima utilizada na produção de morangos e manjericões são: mudas de morangos, sementes de manjericões, espuma fenólica, slabs, solução nutritiva e embalagens dos manjericões e do morango; serão inicialmente comprados de dois fornecedores mapeados na pesquisa, que foram escolhidos pela sua confiabilidade de entrega e qualidade de seus produtos a partir de comentários e pesquisas utilizando a internet.

A maioria dos fornecedores será de fora do Estado, logo, será necessário um prazo de 10 dias para os produtos serem entregues. A política de fornecimento será realizada a partir de descontos na compra de grandes quantidades de seus produtos. O período de entregas será mensal para a maioria dos produtos comprados, porém existirão alguns casos onde a entrega será temporária como no caso das mudas de morango e dos slabs, que possuem um ciclo de vida de aproximadamente dois anos.

No início serão realizados alguns testes com os fornecedores que passaram maior confiança e credibilidade ao longo dos meses antes de se realizar uma parceria, então, haverá um plano de contingência para fornecedores. Ainda, é importante ter em mente que podem surgir outros fornecedores além dos mencionados, conforme se obtém mais conhecimento na área e maior reconhecimento no mercado, podendo aparecer fornecedores interessados em vender seu produto e realizar parcerias. Nesta primeira abordagem para comprar dos materiais necessários para produção, foram escolhidos os fornecedores com melhor custo-benefício, visto que ainda não se teve tempo de experiência com nenhuma empresa fornecedora.

\section{CONSIDERAÇÕES FINAIS}

O estudo realizado permitiu avaliar a viabilidade da produção de morangos e manjericões hidropônicos. Observou-se que os produtos possuem um excelente potencial econômico e poderia ser, inclusive, um dos caminhos para assegurar e 
reforçar o desenvolvimento de setores como da agricultura familiar. A pesquisa sugere que, com pequenos, mas constantes investimentos e incentivo tecnológico, possa ser criadas diversas oportunidades no setor agrícola.

Assim, levando em consideração todos os dados apontados na pesquisa, entende-se que a melhor forma de introduzir os produtos no mercado, seria através de vendas diretas no Ceasa do MS, onde será garantida a venda de todos os produtos, mesmo que a um preço um pouco abaixo do mercado, em que os representantes locais farão todo o intermédio até os compradores, que podem ser restaurantes, mercados, frutarias, sacolões, entre outros.

Os dados coletados permitem afirmar que o mercado no qual pretende-se atuar está em expansão, fato verificado pelos dados apresentados na pesquisa: de um total de 861 toneladas produzidos de morangos, apenas 1 tonelada é produzida em Mato Grosso do Sul, que equivale a cerca de $0,0022 \%$ da produção total. No caso do manjericão a situação é diferente, sendo que de uma produção total de 14,6 toneladas produzidas no total, aproximadamente o Estado produz 13 toneladas que é o equivalente a $89,22 \%$. Assim, o mercado se mostra promissor principalmente no que se refere na produção de morangos.

A realização da análise de mercado é muito importante no gerenciamento de empresas porque permite analisar a viabilidade de um empreendimento e estudar o mercado de forma global e suas características. Essa pesquisa trabalha com diferentes informações que possibilitaram a tomada de decisões de forma mais assertiva, a partir da opinião dos clientes e especialistas, revisões da bibliografia, oferecendo uma sólida base para analisar e projetar o segmento de mercado na qual o empreendimento se desenvolverá. Com os resultados apresentados na pesquisa de mercado entende-se que os objetivos foram alcançados.

Uma limitação encontrada na realização da pesquisa foi a dificuldade em convencer as pessoas a colaborarem com a coleta de dados, uma vez que muitas não entendiam os benefícios que os resultados poderiam trazer aos futuros empreendedores neste setor do agronegócio.

Como sugestão de futuras pesquisas, destaca-se a necessidade de realizar uma pesquisa mais aprofundada sobre os motivos ou pretensões que levam os consumidores a adquirir os produtos com o objetivo de analisar a tendência de mercado e seu consumo e aperfeiçoar os resultados da análise de mercado. 


\title{
Market analysis: strawberry and basil production
}

\begin{abstract}
The potential for development and entrepreneurship has always been a predicate to describe Brazilian agribusiness. In recent decades, the sector has become the focus of major developments and opportunities in the irrigation area, where floriculture has been distinguished in a business way without bias only for subsistence and welfare culture. In this sense, the objective of this quantitative research is to conduct a market analysis that maps and identifies the consumer market segment of strawberry and hydroponic basil cultivation, demonstrating the viability of a new venture in this field. The study has a bibliographic, exploratory, descriptive and explanatory nature and was conducted in the state of Mato Grosso do Sul from 2017 to 2018. The results indicated, through the analyzes carried out about the market, that this segment is in constant expansion and with adequate investment and technological effort, it is possible to create many opportunities related to family farming.
\end{abstract}

KEYWORDS: Market analysis. Agribusiness. Family farming. 


\section{REFERÊNCIAS}

BARROS, A. J. P.; LEHFELD, N. A. S. Fundamentos de metodologia científica. 3. ed. Brasil: Makrov, 2007.

BERNARDI, J.; HOFFMAN, A. Produção de morangos no sistema semi-hidropônico. 2006. Disponível em:

<http://www.cnpuv.embrapa.br/publica/sprod/MorangoSemiHidroponico/muda s.htm>. Acesso em: 10 jun. 2017.

CASA CIVIL. O que é Agricultura Familiar. 2016. Disponível em:

<http://www.mda.gov.br/sitemda/noticias/o-que-é-agricultura-familiar>. Acesso em: 08 fev. 2018.

CEASA. Cotações CEASA-MS. 2016. Disponível em:

<http://www.ceasa.ms.gov.br/cotacoes-ceasa-ms/>. Acesso em: 17 jun. 2017.

GIL, A. C. Como elaborar projetos de pesquisa. 4. ed. São Paulo: Atlas, 2002.

GIL, A. C. Métodos e técnicas da pesquisa social. 5. ed. São Paulo: Atlas, 2007.

IBGE. Índice de Crescimento Populacional. 2017. Disponível em:

<http://www.ibge.gov.br/apps/populacao/projecao/>. Acesso em: 09 ago. 2017.

ISSA, I. B. et al. The contributions of public policies for strengthening family farming and increasing food security: The case of Brazil. Land Use Policy, n. 82, p. 573-584, 2019. crossref

LOSCHIAVO, R. $O$ que é Hidroponia? 2016. Disponível em: <http://www.ecoeficientes.com.br/o-que-e-hidroponia/>. Acesso em: 28 de jan. 2018.

MALDONADO, C. Dos produtos vendidos na Ceasa, $85,51 \%$ são de outras regiões do País. Campo Grande: Jornal Campo Grande News, 2014. Disponível em: $<$ https://www.campograndenews.com.br/rural/dos-produtos-vendidos-na-ceasa85-51-sao-de-outras-regioes-do-pais>. Acesso em: 13 jun. 2017.

MARTINS, P. G.; LAUGENI, F. P. Administração da Produção. 3. ed. São Paulo: Saraiva, 2015. 
MELCHIZEDEK, I. A.; ALLEN, E. M. D. L.; JESS, D. A. D.; ROWENA, M. S. F. On the design of Nutrient Film Technique hydroponics farm for smart agriculture.

Engineering in Agriculture, Environment and Food. In press. 2019.

NEVES, E. M.; NEVES, M. F., O Agronegócio, desenvolvimento brasileiro e a importância da pesquisa. In: Agronegócios e Desenvolvimento Sustentável: Uma Agenda para a Liderança Mundial na Produção de Alimentos e Bioenergia. 2007. Marcos Fava Neves (Coordenador), Disponível em: http://www.favaneves.org/wp-content/uploads/2018/03/Livro-AgronegociosDesenvolvimento-Sustentavel-Fava-Neves-Editora-Atlas-2007.pdf. Acesso em: 01 de jul. 2019.

PORTER, M. Competição estratégias competitivas essenciais. 2. ed. Rio de Janeiro: Campus, 1999.

R7, Notícias. 9 Benefícios do Morango - para que serve e propriedades. 2016. Disponível em: <http://noticias.r7.com/saude/mundo-boa-forma/9-beneficiosdo-morango-para-que-serve-e-propriedades-03022016>. Acesso em: 20 jun. 2017.

BELEZAESAUDE. Manjericão: conheça essa erva maravilhosa. 2016. Disponível em: <https://belezaesaude.com/manjericao/>. Acesso em: 28 mai. 2017.

SEBRAE. Produção de morangos na Bahia. 2017a. Disponível em: <https://www.sebrae.com.br/Sebrae/Portal Sebrae/UFs/BA/Anexos/Produção de morango na Bahia.pdf>. Acesso em: 07 jun. 2017

SEBRAE. Hidroponia: Como montar uma hidroponia. 2017b. Disponível em: $<$ https://www.sebrae.com.br/sites/PortalSebrae/ideias/como-montar-umahidroponia,02387a51b9105410VgnVCM1000003b74010aRCRD>. Acesso em: 24 jun. 2017.

SILVA, A. P. P; MELO, B. Hidroponia. 2003. Disponível em: <http://www.fruticultura.iciag.ufu.br/hidropo.htm>. Acesso em: 30 de mai. 2017.

SOUZA, O. R. G. de; SOUZA, J. D. F. de; CAMPEÃO, P.; JACINTO, L. C. (MS). Agricultura familiar no MS: entre resultados expressivos e decisões políticas deficientes. 2012. Elaborado por EMBRAPA. Disponível em: $<$ https://www.embrapa.br/busca-de-publicacoes/publicacao/939148/agricultura-familiar-no-ms-entre-resultados-expressivos-edecisoes-politicas-deficientes>. Acesso em: 02 fev. 2018. 
TONNEAU, J. P.; SABOURIN, E. Agricultura familiar: interação entre políticas públicas e dinâmicas locais. Porto Alegre: Ufrgs, 2007.

VERGARA, S. C. Projetos e relatórios de pesquisa em administração. 9. ed. São Paulo: Atlas, 2007.

VERGARA, W. R. H. Métodos numéricos computacionais em engenharia. Rio de Janeiro: Ciência Moderna, 2017.

Recebido: 25 Jul. 2019

Aprovado: 10 Out. 2020

DOI: 10.3895/gi.v16n2.10406

Como citar:

VERGARA, W.R.H. et al. Análise de mercado: produção de morangos e manjericões. R. Gest. Industr.,

Ponta Grossa, v. 16, n. 2, p. 186-203, Abr./Jun. 2020. Disponível em: https://periodicos.utfpr.edu.br/revistagi

Correspondência:

Walter Roberto Hernández Vergara

Universidade Federal da Grande Dourados (UFGD), Dourados, Mato Grosso do Sul, Brasil.

Direito autoral: Este artigo está licenciado sob os termos da Licença Creative Commons-Atribuição 4.0

Internacional.

\section{(c) (1)}

